\title{
Minerals and Vitamin-A Status in Relation to Gustatory Functions for Salt in Healthy Female College Students
}

\author{
Tsuguyoshi SuZUKI, ${ }^{1}$ Hiromi ISHIDA, Hisano SUZUKI, ${ }^{2}$ \\ Tetsuro Hongo, Kanae KobAYASHI, Jun YoshinAGA, \\ Tamotsu OHBA, ${ }^{1}$ and Yoshihiro SHIDOJI ${ }^{3}$ \\ ${ }^{1}$ Department of Human Ecology, School of Health Sciences, \\ Faculty of Medicine, University of Tokyo, \\ Bunkyo-ku, Tokyo 113, Japan \\ ${ }^{2}$ Laboratory of Institutional Meal Service, \\ Kagawa Women's College of Nutrition, \\ Sakado, Saitama 350-02, Japan \\ ${ }^{3}$ Department of Biochemistry and Nutrition, \\ School of Health Sciences, Faculty of Medicine, \\ University of Tokyo, Bunkyo-ku, Tokyo 113, Japan
}

(Received May 14, 1987)

\begin{abstract}
Summary Twenty-five healthy female college students were studied for the gustatory function tests for salt $(\mathrm{NaCl})$ and some selected biochemical parameters including plasma retinol and plasma retinol-binding protein (PRBP). Plasma zinc (PZn) and retinol levels were comparable with those of good responders in tests of discrimination between two levels of $\mathrm{NaCl}$ in the previous report, but PRBP was lower in the present subjects. From the results of correlation analysis and stepwise multiple regression analysis, the individual students' discriminability of $\mathrm{NaCl}$ concentrations was related to the parameters regarding metabolic status of calcium $(\mathrm{Ca})$, magnesium $(\mathrm{Mg})$, sodium $(\mathrm{Na})$, and selenium $(\mathrm{Se})$. The detection threshold of $\mathrm{NaCl}$ concentration ranged from 1 to $60 \mathrm{mmol} / \mathrm{liter}$ and was related to PRBP. Plasma Zn was significantly positively correlated with both plasma retinol and PRBP, but significantly negatively correlated only for the detection threshold of $\mathrm{NaCl}$ concentration. On the basis of these results, the importance of vitamin-A nutrition and the relation of minerals such as $\mathrm{Na}, \mathrm{Ca}, \mathrm{Mg}$, and $\mathrm{Zn}$ to the gustatory functions of $\mathrm{NaCl}$ was confirmed and a possible participation of $\mathrm{Se}$ to the functions was suggested.
\end{abstract}

Key Words discrimination between $\mathrm{NaCl}$ concentrations, detection threshold for taste of salt, minerals in plasma and urine, sodium, potas-

${ }^{1}$ 鈴木継美，本郷哲郎，小林香苗，吉永 淳, 大場 保, ${ }^{2}$ 石田裕美，鈴木久乃，

3 四童子好広 
sium, calcium, magnesium, zinc, selenium, plasma retinol-binding protein, retinol

Gustatory function tests of the taste for salt $(\mathrm{NaCl})$ were twice studied in our laboratories in different subject: the first for female college students $(I)$ and the second for male college students(2). The results of two studies were somewhat dissimilar: in the female students, the discriminability of $\mathrm{NaCl}$ concentrations in foods was related positively to plasma zinc (PZn) and plasma retinol levels and negatively to urinary potassium (UK) and sodium (UNa) levels without showing a significant association with the detection threshold for $\mathrm{NaCl}(1)$; in the male students, no significant parameters were found for the discriminability of $\mathrm{NaCl}$ concentration, but the detection threshold for $\mathrm{NaCl}$ was associated with the ratio of urinary calcium $(\mathrm{Ca})$ to magnesium $(\mathrm{Mg})$, plasma $\mathrm{Ca}(\mathrm{PCa})$, plasma sodium $(\mathrm{PNa})$, and discriminability between $\mathrm{NaCl}$ concentrations (2). The differences between the two groups in PZn and PRBP (these were higher in the male than in the female students) as well as in the $\mathrm{Ca}, \mathrm{Mg}$, and $\mathrm{Na}$ metabolism (male students would have engaged in hard physical exercise almost every day and had elevated plasma levels of these minerals) might be the cause of this dissimilarity. However, the minerals $\mathrm{Na}, \mathrm{K}, \mathrm{Ca}, \mathrm{Mg}$, and $\mathrm{Se}$, which were studied in plasma for the male students, were not included in the study on female students. Therefore, it was necessary to study the female students again, adding the minerals in plasma as the items for examination.

In the previous studies, the discrimination test was conducted using only two test-batches, each having a different $\mathrm{NaCl}$ concentration. This mode of testing may be influenced by the examinees' psychological states; therefore, in this study, a "two-batch" mode was compared with a "three-batch" mode in which two of the batches had identical concentrations of $\mathrm{NaCl}$. The lowest $\mathrm{NaCl}$ concentration in the previous threshold testing was $6 \mathrm{mmol} /$ liter, and the threshold in $70 \%$ of female students was at this level, indicating the possible existence of more sensitive responders. Thus, the lowest concentration tested is $1 \mathrm{mmol} /$ liter in the present study.

\section{SUBJECTS AND METHODS}

Subjects. Twenty-five volunteers (age: 18-19 years old) from among the new students at a women's college in 1985 participated in this study. They volunteered for participation after listening to an explanation of the scope, objectives, and methodologies of the study.

Study schedule. The schedule of the study is presented in Fig. 1. In October 1985, the two-batch mode discrimination test was compared with the three-batch mode, and additional three-batch mode tests were conducted in May and June 1986. 


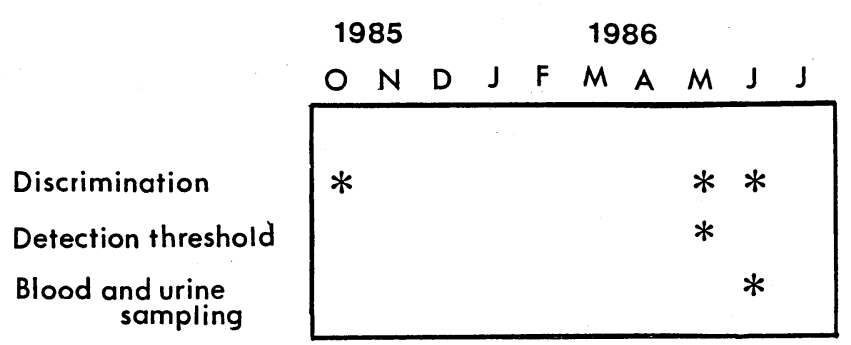

Fig. 1. Schedule of the study: letters represent months, asterisks show the examination dates.

The detection threshold for salt concentration was tested May 29, 1986. Blood and urine were collected at the occasion of the three-batch test in June 1986.

Gustatory function tests. The detection threshold for $\mathrm{NaCl}$ concentration was tested as in the previous study ( 1$)$, and the levels of concentration tested were 1, 3,6, 12,30 , and $60 \mathrm{mmol} /$ liter. In the repetition of tests ( 8 times) with a 4-day interval for selected 5 students, the detection threshold had fluctuated in a narrow range (results will be published elsewhere); thus, errors due to the time-lapse between the threshold test and the blood and urine sampling was expected to be not so large.

As the matrix for discrimination between two levels of $\mathrm{NaCl}$ concentration $(0.6$ and $0.7 \%$ ), water and Japanese-style consommé soup were selected because other matrices tested in the previous two studies yielded low rates (e.g., boiled rice: 50 $74 \%$ ) or high rates (Miso soup : $92-100 \%$ ) of correct discrimination. The two-batch mode of testing was similar to that in the previous studies; for the three-batch mode, it was randomly decided which of two combinations-i.e., two $0.6 \%$ batches and one $0.7 \%$ batch, or one $0.6 \%$ batch and two $0.7 \%$ batches - would be applied to each examinee.

Blood and urine collection. Blood was veni-punctured into a heparinized tube in the afternoon (at least two hours after lunch) of June 2, 1986. Urine samples were collected over a 24 -h period in a week from June 3 to June 9, with instructions for careful collection.

Biochemical analysis. Hemoglobin concentration in blood was measured by the cyan-methemoglobin method. Hematocrit was determined by centrifugation using capillary tubes. Plasma total protein (TP), albumin (ALB), triglycerides (TG), cholesterol (CHO), and activities of plasma enzymes such as aspartate aminotransferase (AST), alanine aminotransferase (ALT), lactate dehydrogenase (LDH), and creatine phosphokinase (CK) were determined using an auto-analyzer (Abbott Bichromatic Analyzer, ABA 200) with clinical chemical reagents supplied by Abbott Laboratories. To ensure the accuracy of determination, a standard serum (Moni-Trol I, American Dade) was measured on every occasion of determination.

Retinol, $\alpha$-carotene, $\beta$-carotene, and $\alpha$-tocopherol in plasma were determined as follows: HPLC (column: YMC-PACK A-302 ODS, $4.6 \times 150 \mathrm{~mm}$; eluent: methanol/butanol $=80 / 20$ containing $0.1 \%$ (v/v) $10 \mathrm{~mm}$ acetate buffer, $\mathrm{pH} 3.6$; flow 
rate: $1.0 \mathrm{ml} / \mathrm{min}$, back pressure $60 \mathrm{kgf} / \mathrm{cm}^{2}$; detector: $\mathrm{UV} /$ visible detector; wavelength: $325 \mathrm{~nm}$ for retinol, $292 \mathrm{~nm}$ for $\alpha$-tocopherol and $\alpha$-tocopheryl nicotinate, $450 \mathrm{~nm}$ for carotenes) after extraction of plasma with ethanol and $n$-hexane. Calibration was conducted by an external standard method with a computer-aided data system, and $\alpha$-tocopheryl nicotinate was used only as a standard for volumecorrection and recovery. Authentic samples of retinol, carotenes, $\alpha$-tocopherol and $\alpha$-tocopheryl nicotinate were purchased from Sigma Chemicals.

Minerals ( $\mathrm{Na}, \mathrm{K}, \mathrm{Ca}, \mathrm{Mg}$, and $\mathrm{Zn}$ ) in plasma and urine were measured by flame atomic absorption spectrometry (Nippon Jarell Ash, Model AA-845); for Ca, lanthanum chloride was added to prevent interference due to phosphate. Selenium (Se) in plasma and erythrocytes was measured by Watkinson's method (3). To check the accuracy of mineral measurements, a reference serum (Natl. Inst. Environ. Studies of Japan, NIES No. 4) was simultaneously measured.

Retinol-binding protein (RBP) in plasma was estimated by radial immunodiffusion (4) using Partigen plates (Hoechst). Creatinine in urine was colorimetrically measured using Jaffe's reaction(5). From the 24-h excretion of creatinine and stature, creatinine height index (CHI) was calculated.

Anthropometry. Height and weight were measured on the occasion of testing the detection threshold; using these, the body mass index-(weight, $\mathrm{kg}$ )/(height ${ }^{2}$, $\mathrm{m}^{2}$ ) - was calculated.

Statistical analysis. Variables whose distribution deviated from the normal distribution for the values of skewness and kurtosis in basic statistics were subjected to logarithm conversion, e.g., the detection threshold. Correlation analysis and stepwise multiple regression analysis were applied to reveal the interrelationship between the variables and to select the variables which may be relevant to gustatory functions (6). To compare the results of discrimination tests for different test modes and different occasions, Fischer's exact probability method or Wilcoxon's matched pairs signed-rank test was used (7).

\section{RESULTS}

\section{Anthropometry, plasma proteins, and some biochemical parameters}

Nothing noteworthy was seen in the stature, weight and body mass index measurements, and no anemic students were found (Table 1). TP, ALB, and CHO in plasma were all in the normal range, but plasma triglycerides (TG) were elevated in two students (404 and $236 \mathrm{mg} / \mathrm{dl}$, respectively; the normal range: $50-130 \mathrm{mg} / \mathrm{dl}$ ). Levels of PRBP were low: the average, $4.0 \mathrm{mg} / \mathrm{dl}$, was lower than those in the previous two samples (female college students: 4.7, and male college students: $5.8 \mathrm{mg} / \mathrm{dl}$ ). Activities of plasma enzymes were all in the normal range except for a single case with very marginal elevation of LDH activity (data not shown).

\section{Gustatory functions}

Discrimination between two levels of $\mathrm{NaCl}$ concentration. Discrimination tests 
Table 1. Anthropometric data and some biochemical parameters.

\begin{tabular}{lccc}
\hline & $n$ & Mean & SD \\
\hline Stature $(\mathrm{cm})$ & 25 & 158.4 & 4.2 \\
Weight $(\mathrm{kg})$ & 25 & 53.2 & 6.8 \\
Body mass index $\left(\mathrm{kg} / \mathrm{m}^{2}\right)$ & 25 & 21.2 & 2.6 \\
Hemoglobin $(\mathrm{g} / \mathrm{dl})$ & 25 & 13.5 & 0.8 \\
Hematocrit $(\%)$ & 25 & 40.6 & 2.2 \\
Plasma total protein $(\mathrm{g} / \mathrm{dl})$ & 25 & 8.0 & 0.5 \\
Plasma albumin $(\mathrm{g} / \mathrm{dl})$ & 25 & 4.3 & 0.15 \\
Plasma RBP $(\mathrm{mg} / \mathrm{dl})$ & 25 & 4.0 & 0.7 \\
Plasma triglycerides $(\mathrm{mg} / \mathrm{dl})$ & 25 & 114 & 71 \\
Plasma cholesterol $(\mathrm{mg} / \mathrm{dl})$ & 25 & 200 & 31 \\
\hline
\end{tabular}

${ }^{\mathrm{a}} \mathrm{RBP}$, retinol-binding protein.

Table 2. Results of salt concentration discrimination.

\begin{tabular}{rccc}
\hline Test matrix & $\begin{array}{c}\text { No. of students } \\
\text { tested }\end{array}$ & $\begin{array}{c}\text { No. of correct } \\
\text { discriminators }\end{array}$ & (\%) \\
\hline Water solution 2-batch (Oct. '85) & 24 & 23 & $(95.8)$ \\
3-batch (Oct. '85) & 24 & 18 & $(75.0)$ \\
3-batch (May '86) & 24 & 11 & $(45.8)$ \\
Japanese-style consommé soup & & & \\
2-batch (Oct. '85) & 24 & 19 & $(79.2)$ \\
3-batch (Oct. '85) & 24 & 15 & $(62.5)$ \\
3-batch (May '86) & 24 & 14 & $(58.3)$ \\
\hline
\end{tabular}

Results of "two-batch" and "three-batch" test modes were compared for the data obtained in October 1985, and no significant difference between two modes was found by Fischer's exact probability: $p=0.596$.

in October 1985 compared the two-batch mode and the three-batch mode using water solution and Japanese-style consommé soup (Table 2). The proportion of correct discriminators was slightly - albeit not statistically significantly ( $p>0.05$ by Fischer's exact probability method)-decreased in the three-batch mode of tests. Consistency of discrimination was compared between the results obtained in October 1985 and those obtained in May and June 1986, both using three-batches: the discrepancy between two occasions was not significant (Wilcoxon's test, $p>0.05$ ). However, the proportion of correct discriminators varied from 46 to $96 \%$ with test matrices, occasions, and test modes (Table 2); and the individual student's rate of correct discrimination (RCD) in repeated tests (one student completed 5 tests; two, 4 tests; 22, 6 tests) ranged from 0 to $100 \%$ (Fig. 2). The present average rate was $70 \%$ which was slightly lower than the previous result $(83.2 \%)$ (Table 3 ). 


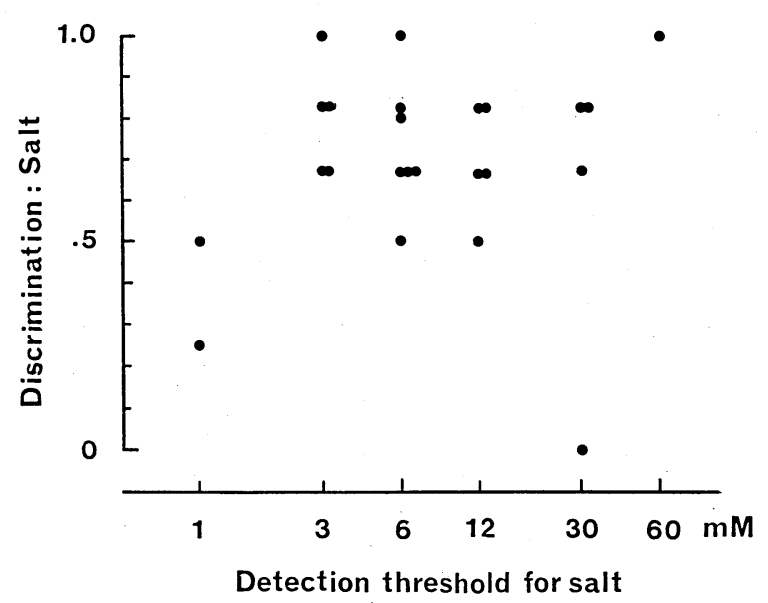

Fig. 2. Relationship between the detection threshold and individual's rate of correct discrimination between $\mathrm{NaCl}$ concentrations. Detection threshold as $\mathrm{mm}$ of $\mathrm{NaCl}$ concentration is on abscissa, and individual's correct discrimination rate in repeated tests (the perfect discrimination: 1.0 ) is on ordinate. Number of subjects: 24 , because one student failed to attend the detection threshold examination.

Table 3. Gustatory functions and vitamins in plasma.

\begin{tabular}{lccc}
\hline & $n$ & Mean & SD \\
\hline RCD $^{\text {a }: \text { Salt }(\%)}$ & 25 & 70.2 & 22.7 \\
Detection threshold for salt $(\mathrm{mmol} / \mathrm{liter})^{\mathrm{b}}$ & 24 & 12.5 & 14.0 \\
Retinol $(\mu \mathrm{g} / \mathrm{ml})$ & 25 & 0.42 & 0.066 \\
$\alpha$-Carotene $(\mu \mathrm{g} / \mathrm{ml})$ & 22 & 0.11 & 0.036 \\
$\beta$-Carotene $(\mu \mathrm{g} / \mathrm{ml})$ & 25 & 0.41 & 0.25 \\
$\alpha$-Tocopherol $(\mu \mathrm{g} / \mathrm{ml})$ & 25 & 7.68 & 1.12 \\
\hline
\end{tabular}

${ }^{\mathrm{a}} \mathrm{RCD}$, rate of correct discrimination. ${ }^{\mathrm{b}}$ Geometric mean and its standard deviation: $7.4 \stackrel{\Upsilon}{2} .9 \mathrm{mmol} / \mathrm{liter}$.

Detection threshold for $\mathrm{NaCl}$ concentration. The level of detection threshold scattered from 1 to $60 \mathrm{mmol} /$ liter, and the log-converted values did not correlate with the individual's rate of correct discrimination (correlation coefficient, $r=0.137$, $p>0.05$ ) (Fig. 2). In this correlogram, a single subject who completely failed in discrimination tests occupied a position far from the general trend. This subject had elevated PCa and PMg levels as mentioned later, but the levels of PCa and PMg in other subjects were all in the normal range. Then, if this subject with complete failure in discrimination tests is excluded, and the subjects with normal PCa and $\mathrm{PMg}$ levels are analyzed, the correlation coefficient will be significant as $r=0.434$ $(p<0.05)$. 
Biochemical analysis concerning minerals and vitamins

Plasma retinol, carotenes, and tocopherol. The levels of plasma retinol, which was measured by fluorometry in the previous study and by HPLC with UV detector in the present study, were in good agreement, i.e., the previous average was 0.39 and the present average was $0.42 \mu \mathrm{g} / \mathrm{ml}$. However, these values were lower than the average for 10 healthy adult males in our laboratory $(0.57 \mu \mathrm{g} / \mathrm{ml}$, also measured by HPLC) (8), presumably reflecting a gender-related difference. Beta-carotene levels were higher and $\alpha$-tocopherol levels were lower in the present subjects than in the adult males, but there are no comparable data for $\alpha$-carotene.

Plasma and erythrocyte minerals. In contrast to the previous result, low levels of PZn were not found: the present average, $0.75 \mu \mathrm{g} / \mathrm{ml}$, corresponded to the level observed in the excellent discriminators in the previous study. The levels of PSe and ESe were comparable with those reported in ordinary Japanese and in our previous male subjects $(9,10)$.

Table 4. Plasma and erythrocyte minerals.

\begin{tabular}{lccl}
\hline & $n$ & Mean & SD \\
\hline PZn $(\mu \mathrm{g} / \mathrm{ml})$ & 25 & 0.75 & 0.09 \\
$\mathrm{PSe}(\mu \mathrm{g} / \mathrm{ml})$ & 25 & 0.13 & 0.011 \\
$\mathrm{ESe}(\mu \mathrm{g} / \mathrm{g})$ & 25 & 0.31 & 0.04 \\
$\mathrm{PCa}(\mu \mathrm{g} / \mathrm{ml})$ & 25 & 98.7 & 4.7 \\
$\mathrm{PMg}(\mu \mathrm{g} / \mathrm{ml})$ & 25 & 25.7 & 2.8 \\
$\mathrm{PCa} / \mathrm{Mg}(\mathrm{mol} / \mathrm{mol})$ & 25 & 2.31 & 0.23 \\
$\mathrm{PNa}(\mathrm{mg} / \mathrm{ml})$ & 25 & 3.29 & 0.17 \\
$\mathrm{PK}(\mathrm{mg} / \mathrm{ml})$ & 24 & 0.17 & 0.01 \\
\hline
\end{tabular}

P, plasma; E, erythrocyte.

Table 5. Daily urinary excretion of minerals and creatinine.

\begin{tabular}{lccc}
\hline & $n$ & Mean & SD \\
\hline $\mathrm{Na}(\mathrm{g} /$ day $)$ & 25 & 2.36 & 0.85 \\
$\mathrm{~K}(\mathrm{~g} / \mathrm{day})$ & 25 & 1.55 & 0.57 \\
$\mathrm{Na} / \mathrm{K}(\mathrm{mol} / \mathrm{mol})$ & 25 & 2.88 & 1.22 \\
$\mathrm{Ca}(\mathrm{mg} /$ day) & 25 & 93.0 & 35.6 \\
$\mathrm{Mg}(\mathrm{mg} /$ day $)$ & 25 & 93.1 & 34.9 \\
$\mathrm{Ca} / \mathrm{Mg}(\mathrm{mol} / \mathrm{mol})$ & 25 & 1.20 & 2.23 \\
$\mathrm{Zn}(\mu \mathrm{g} /$ day) & 25 & 366 & 107 \\
$\mathrm{Se}(\mu \mathrm{g} /$ day $)$ & 25 & 42.8 & 10.7 \\
\hline Creatinine $(\mathrm{g} /$ day) & 25 & 0.95 & 0.19 \\
Creatinine height index $(\mathrm{mg} / \mathrm{cm})$ & 25 & 6.01 & $1: 09$ \\
\hline
\end{tabular}

Vol. 34, No. 2, 1988 
Table 6. Correlation matrix between various parameters examined.

\begin{tabular}{|c|c|c|c|c|c|c|c|c|c|c|c|c|c|c|}
\hline ALB & $\mathrm{CHO}$ & TG & $\mathrm{PZn}$ & PSe & $\mathrm{ESe}$ & $\mathrm{PCa}$ & $\mathrm{PMg}$ & $\mathrm{PNa}$ & PK & AST & ALT & $\mathrm{LDH}$ & CK & $\mathrm{UZn}$ \\
\hline \multirow[t]{14}{*}{-} & - & - & - & .443 & - & - & - & - & - & - & - & - & -.511 & - \\
\hline & - & -.524 & - & - & - & - & - & - & - & - & - & - & - & - \\
\hline & & - & - & - & - & - & - & - & .508 & - & .516 & .444 & - & - \\
\hline & & & - & - & - & - & - & - & - & - & - & - & - & - \\
\hline & & & & - & - & - & - & - & - & - & - & - & - & - \\
\hline & & & & & - & .542 & - & - & - & - & - & - & - & - \\
\hline & & & & & & - & - & .435 & - & - & - & - & - & - \\
\hline & & & & & & & - & - & .489 & - & - & - & - & - \\
\hline & & & & & & & & - & - & - & .513 & - & - & - \\
\hline & & & & & & & & & - & - & - & - & - & - \\
\hline & & & & & & & & & & - & - & - & - & - \\
\hline & & & & & & & & & & & - & - & - & - \\
\hline & & & & & & & & & & & & - & - & - \\
\hline & & & & & & & & & & & & & - & $\overline{438}$ \\
\hline
\end{tabular}

Figures in the table are statistically significant correlation coefficients $(p<0.05)$. ALB, albumin; CHO, cholesterol; TG, triglycerides; PZn, plasma zinc; PSe, plasma selenium; $\mathrm{ESe}$, erythrocyte selenium; $\mathrm{PCa}$, plasma calcium; $\mathrm{PMg}$, plasma magnesium; $\mathrm{PNa}$, plasma sodium; PK, plasma potassium; AST, asparate aminotransferase; ALT, alanine aminotransferase; LDH, lactate dehydrogenase; CK, creatine phosphokinase; UZn,

A single case had elevated levels of PCa $(115 \mu \mathrm{g} / \mathrm{ml})$ and $\mathrm{PMg}(33.4 \mu \mathrm{g} / \mathrm{ml})$, who completely failed in discrimination tests as mentioned; others were all in the normal range, and no elevation of PNa and PK levels was observed (Table 4).

Urinary excretion of minerals and creatinine. Creatinine height indices in the present subjects were slightly smaller than those we reported in adult Japanese females(11). The difference may have resulted from the age difference. Daily excretions of minerals were all within the normal variation range (Table 5).

\section{Correlation and regression analyses}

Correlation analysis revealed that the log-converted detection threshold was negatively correlated with PRBP, plasma retinol, UMg, or PZn, and RCD was 


\begin{tabular}{|c|c|c|c|c|c|c|c|c|c|c|c|c|c|}
\hline USe & $\mathrm{UCa}$ & $\mathrm{UMg}$ & $\mathrm{UNa}$ & UK & $\mathrm{CHI}$ & RBP & Ret & $\beta-\mathrm{C}$ & $\alpha-\mathrm{C}$ & Toc & THD & $\mathrm{RCD}$ & \\
\hline- & - & - & -.482 & - & - & - & - & - & - & - & - & - & TP \\
\hline- & - & - & - & - & - & - & - & - & - & - & - & - & ALB \\
\hline - & -.403 & - & -.450 & - & -.421 & - & - & - & - & .806 & - & - & $\mathrm{CHO}$ \\
\hline- & - & - & - & - & - & - & - & - & - & - & - & - & TG \\
\hline- & - & - & - & - & - & .490 & .514 & - & -.562 & - & -.421 & - & $\mathrm{PZn}$ \\
\hline .424 & - & - & - & -.399 & -.594 & - & - & -.406 & - & - & - & -.490 & PSe \\
\hline - & - & - & - & - & - & - & - & .506 & - & - & - & - & $\mathrm{ESe}$ \\
\hline- & - & - & - & - & - & - & - & - & - & - & - & -.623 & $\mathrm{PCa}$ \\
\hline- & - & - & - & - & - & - & - & - & - & - & - & - & $\mathrm{PMg}$ \\
\hline- & - & - & - & - & - & - & - & - & - & - & - & .434 & $\mathrm{PNa}$ \\
\hline- & - & - & - & - & - & - & .585 & - & - & - & - & - & PK \\
\hline- & - & - & - & - & - & - & - & - & - & - & - & - & AST \\
\hline- & - & - & - & - & - & - & - & - & - & .398 & - & - & ALT \\
\hline- & - & - & - & - & - & - & - & - & - & .400 & - & - & LDH \\
\hline- & .439 & - & - & - & - & - & - & - & - & - & - & - & CK \\
\hline \multirow[t]{13}{*}{-} & .480 & - & - & - & - & - & - & - & - & - & - & - & $\mathrm{UZn}$ \\
\hline & - & .399 & - & .532 & .567 & - & - & - & - & - & - & - & USe \\
\hline & & .477 & .497 & - & - & - & - & - & - & -.449 & - & - & $\mathrm{UCa}$ \\
\hline & & & .425 & - & - & - & - & - & - & - & -.470 & -.452 & $\mathrm{UMg}$ \\
\hline & & & & - & - & - & - & - & - & - & - & - & UNa \\
\hline & & & & & .471 & - & - & .503 & - & - & - & - & UK \\
\hline & & & & & & - & - & - & - & - & - & - & $\mathrm{CHI}$ \\
\hline & & & & & & & .909 & - & - & - & -.580 & - & RBP \\
\hline & & & & & & & & - & - & - & -.559 & - & Ret \\
\hline & & & & & & & & & .548 & - & - & - & $\beta-\mathrm{C}$ \\
\hline & & & & & & & & & & - & - & - & $\alpha-C$ \\
\hline & & & & & & & & & & & - & .402 & Toc \\
\hline & & & & & & & & & & & & - & THD \\
\hline
\end{tabular}

urinary zinc; USe, urinary selenium; $\mathrm{UCa}$, urinary calcium; $\mathrm{UMg}$, urinary magnesium; $\mathrm{UNa}$, urinary sodium; UK, urinary potassium; CHI, creatinine height index; RBP, retinol-binding protein; Ret, retinol; $\beta$-C, $\beta$-carotene; $\alpha$-C, $\alpha$-carotene; Toc, $\alpha$-tocopherol; THD, the detection threshold for salt; RCD, rate of correct discrimination of salt concentrations.

negatively correlated with PCa, PSe or UMg and positively with PNa or plasma $\alpha$ tocopherol (Table 6).

Among other sets of significant correlations, of remarkably high significance $(p<0.001)$ were PRBP vs. plasma retinol $(r=0.909)$ and PCHO $v s$. plasma $\alpha-$ tocopherol $(r=0.806)$. Plasma $\mathrm{Zn}$ was correlated significantly positively with either PRBP or plasma retinol.

Scrutinizing the most highly significant correlation with $\mathrm{RCD}$, that with $\mathrm{PCa}$ (Fig. 3), it is apparent that the existence of a single subject who completely failed all the discrimination tests and had an abnormally elevated PCa level contributed to this high level of significance. This same individual also possessed an elevated PMg level, as mentioned. If this case were excluded, the correlation coefficient would be 


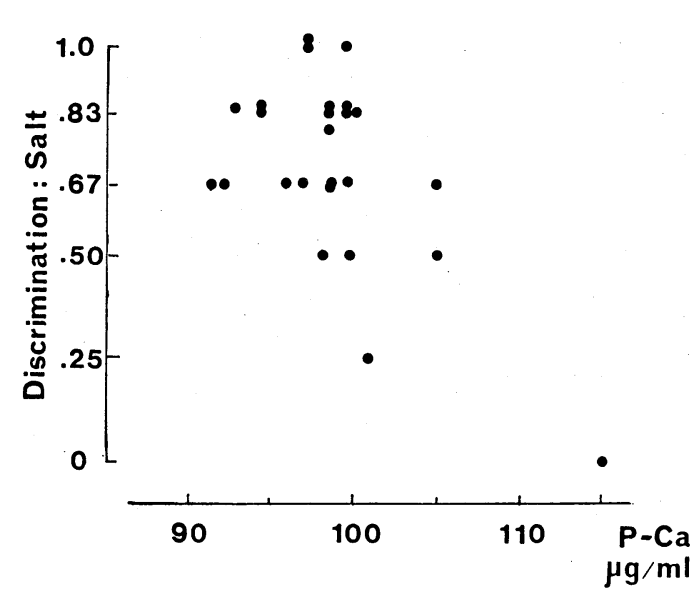

Fig. 3. Correlation of plasma calcium level with individual's rate of correct discrimination.

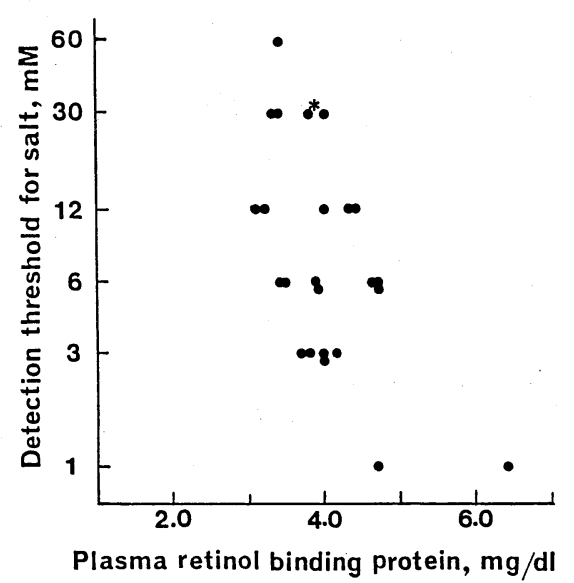

Fig. 4. Correlation of plasma retinol-binding protein level with the detection threshold. Asterisk indicates the case with elevated plasma $\mathrm{Ca}$ and $\mathrm{Mg}$ levels.

$-0.299(p>0.05)$, not a significant correlation. This means that the elevated PCa (and/or PMg) may be a significant factor in controlling discriminability, but for most of the subjects whose PCa levels are in normal range, some other factors must be identified in relation to RCD. Among several significant correlations with RCD in the correlation matrix, which was calculated including the high-PCa case discussed above, that between PSe and RCD lost its significance but others remained significant, and no new significant correlations appeared after exclusion of the high-PCa case.

In the matrix of correlation with the detection threshold, the structure did not change with exclusion of the high-PCa subject: the largest correlation coefficient 
Table 7. Results of stepwise regression analysis.

\begin{tabular}{lccc}
\hline $\begin{array}{c}\text { Dependent } \\
\text { variable }\end{array}$ & $\begin{array}{c}\text { Independent } \\
\text { variables }\end{array}$ & $\begin{array}{c}\text { Standardized partial } \\
\text { regression coefficient }\end{array}$ & $t$-Value \\
\hline $\mathrm{RCD}$ & $\mathrm{PCa}$ & -.613 & $-5.68^{* * *}$ \\
$(\mathrm{R}=0.883)$ & $\mathrm{UMg}$ & -.481 & $-4.47^{* *}$ \\
& $\mathrm{PNa}$ & .415 & $3.85^{* *}$ \\
\hline $\mathrm{RCD}$ & $\mathrm{PNa}$ & .589 & $4.30^{* *}$ \\
$(\mathrm{R}=0.821)$ & $\mathrm{PSe}$ & -.513 & $-3.75^{* *}$ \\
& $\mathrm{UMg}$ & -.472 & $-3.49^{* *}$ \\
-------- & -.580 & $-3.27^{* *}$ \\
$\mathrm{THD}$ & $\mathrm{RBP}$ & & \\
\hline
\end{tabular}

$\mathrm{RCD}$, rate of correct discrimination; $\mathrm{RCD}^{\prime}$, the result after exclusion of one case with abnormally elevated $\mathrm{PCa}$ and $\mathrm{PMg}$ levels; $\mathrm{R}$, multiple correlation coefficient; THD, the detection threshold; RBP, retinol-binding protein. ${ }^{* * . * * *}$ : $p<0.01, \quad p<0.001$, respectively.

found between PRBP and the threshold $(r=-0.580)$ was almost unchanged at -0.587 (Fig. 4); other significant correlations also remained as being significant, and no new significant correlations emerged.

Stepwise multiple regression analysis revealed that the primary variable was $\mathrm{PCa}$, the secondary was $\mathrm{UMg}$, and the tertiary was $\mathrm{PNa}$ as significant factors in explaining the variation of RCD in the subjects of this study as a group; but when the single case with elevated $\mathrm{PCa}$ and $\mathrm{PMg}$ levels was excluded, the significant explanatory factors were $\mathrm{PNa}$, PSe, and $\mathrm{UMg}$. For variation of the detection threshold, PRBP was the only significant factor for the entire group of subjects, and after exclusion of the high-PCa case, $\mathrm{UMg}$ and hemoglobin concentration were added as significant factors (data are not shown in the table) (Table 7).

\section{DISCUSSION}

The present levels of PZn and plasma retinol were in good agreement with those in good discriminators among the female subjects in the previous study $(l)$, but the level of PRBP was lower in the present subjects. The pattern of interrelation of these three parameters- $-\mathrm{PZn}$, plasma retinol, and PRBP-was different between the previous and the present studies: correlation between PRBP and plasma retinol was very strong $(r=0.909)$, and correlations between $\mathrm{PZn}$ and plasma retinol and between PZn and PRBP were both positively significant in the present subjects $(r=0.514$ and 0.490 , respectively), while correlation between PRBP and plasma retinol was moderate $(r=0.581)$, PZn's correlation with plasma retinol was not significant and that with PRBP was significant but weak $(r=0.255)$ in the previous 
study(1). Normally, in the blood, plasma retinol and PRBP is understood to circulate in a $1: 1$ molar complex with little unbound RBP present, and the molar ratio over 1.0 indicates the existence of apo- $\mathrm{RBP}(12)$. In the present subjects, the ratio $(\mathrm{RBP} /$ retinol) was 1.3 on average and it was 1.6 in the previous study. Despite the methodological difference between the two studies in measuring plasma retinol, the existence of apo-RBP is common. Thus, a question arises from this result: Among the following 4 chemical compounds, retinol, holo-RBP, apo-RBP, and $\mathrm{RBP}$, which is responsible in regulating the detection threshold for salt? The amount of apo-RBP, which can be calculated from the values of retinol and RBP by the formula: $(\mathrm{RBP} / 21,000$ - retinol/286) $\times 21,000$, only weakly correlated with the threshold $(r=-0.418, p=0.042)$. If all retinol exists to be bound to RBP, the amount of retinol will represent the amount of holo-RBP. The correlation coefficient between retinol and the threshold was $-0.5592(p=0.005)$, being slightly smaller than that between RBP and the threshold $(r=-0.5804, p=0.003)$. From this minute difference in the value of coefficients, we hesitate to draw any conclusive statement. This is to be further clarified.

An association between $\mathrm{Zn}$ and $\mathrm{RBP}$ has been reported in human studies on pathological conditions such as hepatic diseases, malnutrition, and others (12-14). Animal experiments have repeatedly demonstrated the impaired hepatic mobilization of vitamin A and a depression of RBP in the plasma and liver of $\mathrm{Zn}$-deficient animals (13). Nevertheless, an association between PZn, plasma retinol, and PRBP in apparently healthy human populations has not been described as evidently as in the present paper. From this association, we can postulate that even in the normal fluctuation range of $\mathrm{Zn}$ nutriture, $\mathrm{Zn}$ influences the vitamin A metabolism, although the exact mechanism is not known. Since the turnover rate of RBP is very rapid (biological half-life is $11.1-11.7 \mathrm{~h}$, with a synthesis rate of $190 \mathrm{mg} / \mathrm{m}^{2} /$ day in young men) (15) and in contrast, the biological half-life of $\mathrm{Zn}$ is as long as $930 \mathrm{~d}(16)$, a rapid change of $\mathrm{PRBP}$ is liable to occur while $\mathrm{PZn}$ is rather stable. Moreover, $\mathrm{PZn}$ levels did not change significantly during the menstrual cycle in women $(17,18)$, though PRBP levels did. Therefore, a follow-up observation with repeated monitorings of vitamin $A$ and $\mathrm{Zn}$ nutrition is needed to clarify the changing pattern of interrelation among PZn, plasma retinol, and PRBP.

Ability to discriminate between $\mathrm{NaCl}$ concentrations was completely lost in one subject with elevated $\mathrm{PCa}$ and $\mathrm{PMg}$ (other parameters were all normal) in the present study. This subject's discriminability and plasma minerals were re-examined in January 1987, at which time she discriminated two $\mathrm{NaCl}$ concentrations $(0.6$ and $0.7 \%$ ) and her plasma mineral values were all in the normal range. Thus, $\mathrm{PCa}$ and/or PMg is most likely to be relevant to gustatory functions under normal $\mathrm{Zn}$ and vitamin A nutritional conditions. In our previous study of male college students, the detection threshold for $\mathrm{NaCl}$ was related to urinary $\mathrm{Ca} / \mathrm{Mg}, \mathrm{PCa}, \mathrm{PNa}$ and discriminability also within the normal levels of PZn and PRBP(2). In the present regression analysis, $\mathrm{PNa}$ remained unchanged and $\mathrm{PSe}$ and $\mathrm{UMg}$ appeared as significant independent variables to explain RCD after removal of the high PCa 
and PMg subject. Hence, the metabolic status of not only $\mathrm{Ca}$ and $\mathrm{Mg}$, but also $\mathrm{Na}$, deserves particular attention in the study of gustatory functions for $\mathrm{NaCl}$. For the unexpected participation of PSe, we cannot find any plausible interpretation. In the document of WHO dealing with "Principles and Methods for the Assessment of Neurotoxicity Associated with Exposure to Chemicals" (19), selenium is listed as an example chemical which induces human taste alteration, but we cannot find the scientific evidence in the text and in the literature cited in this document. An association between $\mathrm{Zn}$ and Se was noticed in the previous study of male college students (2), but not in the present subjects; however, there was a significant correlation between PSe and PCa. Thus, it is of further concern to elucidate whether the participation of Se in gustatory functions is merely coincidental.

Finally, the relation of RCD and the detection threshold must be discussed. As already mentioned in the RESULTS section, a significantly positive correlation appeared between these two functions after removal from the sample of a subject with complete failure in discrimination tests, who had elevated PCa and PMg (Fig. 2). This means that a keener detection of $\mathrm{NaCl}$ concentration is accompanied by duller discrimination between $\mathrm{NaCl}$ concentrations in the subjects within normal ranges of $\mathrm{PCa}$ and $\mathrm{PMg}$. The $\mathrm{NaCl}$ concentrations used for discrimination were 0.6 and $0.7 \%$, or 100 and $120 \mathrm{~mm}$, respectively; and the lowest concentration detected was $1 \mathrm{~mm}$ in the present subjects. Therefore, the neural response to $\mathrm{NaCl}$ concentrations in the discrimination tests might have been modified to result in a loss of discriminability in the cases more sensitive to changes in $\mathrm{NaCl}$ concentration. For clarification, we need to examine the discriminability using various $\mathrm{NaCl}$ concentrations with reference to the detection threshold. The reason we selected 0.6 and $0.7 \%$ as the test concentration for discrimination was that in the preliminary results, 70 to $80 \%$ of examinees responded correctly at these concentrations. These concentrations have practical significance in ordinary cooking of less salty dishes. If this discrimination test is useful for detecting mild zinc or vitamin-A deficiency, the optimum concentrations of $\mathrm{NaCl}$ can be searched for more extensively in relation to meticulous consideration of other nutritional parameters related to gustatory functions.

\section{REFERENCES}

1) Ishida, H., Takahashi, H., Suzuki, H., Hongo, T., Suzuki, T., Shidoji, Y., and Yoon, K. H. (1985): Interrelationship of some selected nutritional parameters relevant to taste for salt in a group of college-aged women. J. Nutr. Sci. Vitaminol., 31, 585-598.

2) Suzuki, T., Ishida, H., Suzuki, H., Hongo, T., Kobayashi, K., Yoshinaga, J., and Igawa, S. (1987): Minerals in plasma and urine and gustatory function tests for salt in a group of healthy young men. J. Nutr. Sci. Vitaminol., 33, 289-297.

3) Watkinson, J. H. (1966): Fluorometric determination of selenium in biological material with 2,3-diaminonaphthalene. Anal. Chem., 38, 92-97.

4) Mancini, G., Carbonara, A. O., and Heremans, J. F. (1965): Immunochemical quantitation of antigens by single radial immunodiffusion. Immunochemistry, 2, 235254.

Vol. 34, No. 2, 1988 
5) Bonsnes, R. W., and Taussky, H. H. (1945): On the colorimetric determination of creatinine by the Jaffe reaction. J. Biol. Chem., 158, 581-591.

6) Hull, C. H., and Nie, N. H. (1981): SPSS Update 7-9, McGraw-Hill, Inc., New York, pp. $94-121$.

7) Ishii, S. (1975): Seibutsu Tokeigaku Nyumon (Introduction to Biological Statistics), Baifukan, Tokyo, pp. 107-109 and 125-127.

8) Shidoji, Y., Hosoya, N., Hongo, T., Suzuki, T., Kabuto, M., and Neriishi, K. (1986): Diurnal variation of plasma $\beta$-carotene concentrations in healthy adult males. $J$. Vitamin Soc. Jpn., 60, 300 (Abstract for the 38th General Assembly of the Vitamin Society of Japan).

9) Hongo, T., Watanabe, C., Himeno, S., and Suzuki, T. (1985): Relationship between erythrocyte mercury and selenium in erythrocyte, plasma and urine. Nutr. Res., 5, 12851289.

10) Kurahashi, K., Inoue, S., Yonekura, S., Shimoishi, Y., and Toei, K. (1980): Determination of selenium in human blood by gas chromatography with electroncapture detection. Analyst, 105, 690-695.

11) Suzuki, T., Inaoka, T., and Kawabe, T. (1984): Creatinine height index in a sample of Japanese adults under sedentary activities. J. Nutr. Sci. Vitaminol., 30, 467-473.

12) Underwood, B. A. (1984): Vitamin A in animal and human nutrition, in The Retinoids. Vol. 1, ed. by Sporn, M. B., Roberts, A. B., and Goodman, D. S., Academic Press, Orlando, pp. 282-392.

13) Solomons, N. W., and Russell, R. M. (1980): The interaction of vitamin A and zinc: implications for human nutrition. Am. J. Clin. Nutr., 33, 2031-2040.

14) Goodman, D. S. (1984): Plasma retinol-binding protein, in The Retinoids, Vol. 2, ed. by Sporn, M. B., Roberts, A. B., and Goodman, D. S., Academic Press, Orlando, pp. 42-89.

15) Vahlquist, A., Peterson, P. A., and Wibell, L. (1973): Metabolism of the vitamin A transporting protein complex. Eur. J. Clin., Invest., 3, 352-362.

16) Williams, D. R., and Halstead, B. W. (1982-83): Chelating agents in medicine. J. Clin. Toxicol., 19, 1081-1115.

17) Hagenfeldt, K., Plantin, L. O., and Diczfalusy, E. (1973): Trace elements in the human endometrium. Acta Endocrinol., 72, 115-126.

18) Vahlquist, A., Johnsson, A., and Nygren, K-G. (1979): Vitamin A transporting plasma proteins and female sex hormones. Am. J. Clin. Nutr., 32, 1433-1438.

19) World Health Organization (1986): Environmental Health Criteria 60, Principles and Methods for the Assessment of Neurotoxicity Associated with Exposure to Chemicals, WHO, Geneva, p. 19. 